\title{
Educational Program About Reproductive Health for Blind and Deaf Adolescent Girls in Assiut Governorate
}

\author{
Safaa R. Osman, Mahmoud S. Zakherah \& Soad S. Bayomi. \\ Community Health Nursing Department, Faculty of Nursing, Assiut University, \\ Obstetrics and Gynecology department, Faculty of medicine, \\ Assistant Professor of Community Health Nursing Faculty of Nursing, Assiut University.
}

\begin{abstract}
Background: Persons with disabilities represent a significant portion of the world's population and they are part of every community. They find that information on reproductive health $(\mathrm{RH})$ is often inaccessible to them.

Aim: evaluate the impact of an educational program about RH for blind and deaf adolescent girls. Methods: it was Quasi-experimental research design which conducted in Al Noor and Al Amal Schools in Assiut Governorate. The total sample was 80 girls. Tools: it included three tools: - a structured interview sheet, to assess disabled girls' knowledge and attitudes towards RH and an observational checklist (using doll) to assess practice related perineal care. Results: All the studied sample (100\%) has poor knowledge regarding to RH in pre test while their knowledge improved in post test to 58.8\%. Regarding to perineal care, all of the studied sample (100\%) carried out all steps of perineal care except three steps which include the correct direction for cleaning the perineum, while their practice improved in post and follow up test. Conclusion: All the studied girls have poor knowledge in pre test while after implementation the education programe their knowledge were improved $(\mathrm{P}=\leq 0.001)$.

Recommendation: Continues health education programs should be implemented for increasing awareness of them about reproductive health.
\end{abstract}

\section{Keywords: Reproductive Health, Adolescent, Disabilities \& Perineal care}

\section{Introduction}

Adolescence is one of life's most fascinating and complex stages of human life. The World Health Organization (WHO) defines adolescents as young people aged 10-19 years. Attitudes and behaviors formed in the physical and psychological maturation process are crucial to the current and future Reproductive Health (RH) of individuals, and affect the well-being of their families and communities (USAID, 2001; UNICEF, 2012 \&WHO, 2013).

Persons with disabilities represent a significant portion of the world's population and are part of every community. About 10 percent of the world's population, 650 million people, live with a disability. Approximately 1.4 million children in the world are blind; $75 \%$ of them live in developing countries. Persons with disabilities often face stigma, discrimination, violence and poverty also, being female and disabled has been described as 'double jeopardy'. They experience the deprivation of opportunities in all aspects of life, including access to essential services (I LO, 2009; WHO, 2009 \& Smeltzer, 2013).

Reproductive Health is a state of complete physical, mental and social well-being and not merely the absence of disease or infirmity, in all matters relating to the reproductive system, and to its functions and processes. Reproductive health therefore implies that people are able to have a satisfying and safe sex life and that they have the capability to reproduce and the freedom to decide if, when and how often to do so (WHO, 2008).

People who are blind, deaf, or have intellectual or cognitive impairments find that information on reproductive health is often inaccessible to them. In particular, their sexuality has been ignored and their reproductive rights denied. Informing young persons with disabilities about RH is often difficult because parents, educators, and RH counselors often do not know how to broach the subject. As a result, many young people with disabilities do not receive even basic information about how their bodies develop and change as they mature (UNFPA, 2009, WHO, 2009 \& TARSHI, 2010).

Raising awareness about RH for persons with disabilities frequently requires fighting misconceptions, stigma, and discrimination in communities. A key message is that negative attitudes and barriers in societies are often more disabling than the actual impairments. Community health nurses are in a prime position to advocate for the health needs of the disabled person. (Allender et al., 2005 \& WHO, 2011). 


\section{The aim of this study was}

to assess the knowledge, attitude and practice of disabled adolescent girls. Pre, post implementation of the educational program about reproductive health.

\section{Subject and methods}

\section{I- Research design}

Quasi-experimental research design used to carry out this study.

\section{II- Setting}

The study was conducted in Al-Noor School for blind and Al-Amal School for deaf girls in Assiut

Governorate.

\section{III- Subjects}

\section{Sampling}

The total studied sample was 80 girls (50 girls from Al Amal School and 30 girls from Al Noor School) aged from 11 to 20 years were selected through a convenient sample technique.

\section{Methods}

\section{Preparatory stage}

An official letter approval was obtained from the Dean of Faculty of Nursing, Assiut University, to Directorate of Education and from the Directorate to Central Agency for Public Mobilization and Statistics after that to Centralized management of security finally to directors of schools. The letter included a permission to carry out the study and before carrying out this study preliminary visits to schools were done to develop good communication with leaders, teachers and students.

Tools developed and translated into Arabic form and to ensure the validity of this tool, it was checked and revised by panel of three experts from community and gynecology nursing at Assiut University who reviewed the instrument for clarity, relevance, comprehensiveness, understanding and applicability. After development of the tools, pilot study was carried out before starting of data collection on 7 students (3 student from Al Noor School and 4 students from Al Amal School) randomly.

An educational program developed which included the theoretical part based on the relevant literatures, translated into Arabic module for deaf girls. In addition, it translated into Braille module for blind girls in Specialized Center to communicate with the deaf and blind affiliated to Faculty of Education, Assiut University. The researchers discuss the questionnaire and program to teacher in Al Amal school for deaf girl to translate it into sign language during discussion.

Technical design

The study is dividing into 3 phases:

\section{Pre-intervention phase}

This questionnaire contains four parts which developed and used by the researcher to collect the following data:

Part (1) : Students' socio-demographic data; It was included socio-demographic data of disabled girls as name, age, grad, residence either in school or with family, family size, parent's level of education and occupation and source of RH information.

Menstrual history: It was included age at menarche, period of menses, average days per cycle, towels used per day, and signs and symptoms associated with menstruation.

Part (2) : Knowledge of disabled adolescent girls about reproductive health which include definition of $\mathrm{RH}$, target group of caring, factors affecting it, component of reproductive health, reproductive right. Definition of adolescence, its stages and changes during puberty. Questions about menstruation, which include definition, age at menarche, period of menses, averages days per cycle, characteristics of normal secretion and premenstrual syndrome. Basic anatomy of reproductive system (inside and outside). Premarital examination, which include (the importance of a premarital examination).

A scoring system for assessing the student's knowledge contains of 21 questions The total grade of knowledge equal (79); a score of one was given for each correct answer and a score of zero was given for an incorrect answer or I don't know. Knowledge score divided into poor: <50\%, pass: $50-70 \%$ and good: > 70\% (Ibrahim et al., 2009).

Part (3) : Likert - type scale was developed to assess disabled girls' attitudes towards reproductive health. The responses were based on a three-point likert scale (agree, uncertain and disagree). Attitude scale contains 13 statements, items scored $(2,1$, and 0$)$ respectively, the scoring reversed for negative statements. Total score calculated by summing up and convert into a percent. The respondent's attitude was considered positive if $60 \%$ or higher and negative if less than $60 \%$ (Ibrahim et al, 2009).

Part (4) : An observational checklist was used to assess practice of disabled adolescent girls related perineal care (by using doll). This tool consisted from 8 items each girl trained to perform the procedure by using doll. The tool modified to use as self perineal care during menstruation from Mohamed \& ElNagger, (2012). The tool translated into Arabic form and to ensure the validity of this tool, it was checked and revised by panel of three experts from community and gynecology nursing at Assiut University who reviewed the instrument for clarity, relevance, comprehensiveness, understanding and applicability.

These tools were done three times for the same girls, the first time before intervention, the second time immediately after intervention and the third time after 
three months from intervention. Before starting pre test, the researcher provided orientation for disabled students on how to use the doll in order to minimize the anxiety likely in an unfamiliar object, foster understanding, acceptance it and for respecting them.

The procedure consists of 8 steps as the following

1. Prepare equipment.

2. Wash hands before each perineal care

3. Remove soiled pad from front to back and discard in waste container.

4. Pour warm water or cleansing solution over perineum without opening labia.

5. Clean perineum according to the following direction:

a) Clean the mons pubis from the level of clitoris upward to the lower abdomen.

b) Clean two thighs from medial to lateral.

c) Clean two labia majora from upward to downward in a single motion.

6. Dry the perineum using the same technique

7. Put clean perineal pad.

8. Wash hands after each perineal care.

\section{Intervention phase}

Teaching place

The program was conducted in the classes, residence of girls in school and computer room in Al Amal School.

\section{Teaching Time}

The time of teaching was decided according to the attendance of students and the coordination between the researcher and girls (2 days / week about 30 minutes every time).

\section{Teaching methods and materials}

Before implementing the educational program the researcher prepared simple teaching methods to be used; as lecture (translated into Arabic for deaf girls and Braille to blind girls), and discussion. In addition, all lectures prepared to power point presentation for deaf girl, use of blackboard, picture and handouts.

The arrangement of conducting the program

The studied sample were divided into 9 groups in a variety of numbers ranged between (8-10) girls in each group. Other facilities were checked and arranged during this phase as the teaching place, audiovisual aids, handout, teacher who assist the researcher in Al Amal School etc...

\section{The educational program}

The general objective of the educational program is to promote the awareness of disabled adolescent girls about reproductive health in Assiut Governorate. The researcher collected the data during the period from first of November, 2012 to the end of May, 2013.

\section{Content of the program}

1. Overview about reproductive health which include (definition of RH, target group of caring, factors affecting it, component of reproductive health, Reproductive right).

2. Adolescence which include (definition of adolescent period, stages of adolescence, and physical changes during puberty).

3. Basic anatomy of reproductive system.

4. Menstruation, premenstrual syndrome and Steps of perineal care.

5. Premarital examination

\section{III- Evaluation phase}

The evaluation was done through post test which done immediately after implementing and completing the course to assess disabled adolescent girl' knowledge about reproductive health. Follow up test which was done after 3 months of completing the educational program.

\section{Statistical Analysis}

- The data obtained were reviewed, prepared for computer entry, coded, analyzed and tabulated. Descriptive statistics (i.e., frequencies, percentage, mean and standard deviation, etc) was done using computer program SPSS version 16.

- Chi-square test used to compare differences in the distribution of frequencies among different groups. It is considered * significant when $\mathrm{P}$ values were less than 0.05 or $(\mathrm{P}<0.05)$. 


\section{Results}

Table (1): Distribution of disabled adolescent girls according to their socio-demographic characteristics at El-Amal and El-Noor Schools, Assiut Governorate, $(\mathbf{n}=\mathbf{8 0})$.

\begin{tabular}{|c|c|c|}
\hline Characteristics & No. & $\%$ \\
\hline \multicolumn{3}{|l|}{ Age } \\
\hline$<16$ years & 26 & 32.5 \\
\hline $16-<18$ years & 29 & 36.2 \\
\hline$\geq 18$ years & 25 & 31.2 \\
\hline Mean \pm SD (Range) & \multicolumn{2}{|c|}{$16.27 \pm 2.21(12-20)$} \\
\hline \multicolumn{3}{|l|}{ School } \\
\hline El-Amal & 50 & 62.5 \\
\hline El-Noor & 30 & 37.5 \\
\hline \multicolumn{3}{|l|}{ Grades } \\
\hline Primary & 17 & 21.3 \\
\hline Preparatory & 29 & 36.2 \\
\hline Secondary & 34 & 42.5 \\
\hline \multicolumn{3}{|l|}{ Residence in school } \\
\hline Yes & 78 & 97.5 \\
\hline No & 2 & 2.5 \\
\hline \multicolumn{3}{|l|}{ Place of residence with family } \\
\hline Rural & 74 & 92.5 \\
\hline Urban & 6 & 7.5 \\
\hline \multicolumn{3}{|l|}{ Father's education } \\
\hline Illiterate & 53 & 66.2 \\
\hline Read \& write & 2 & 2.5 \\
\hline Primary & 1 & 1.2 \\
\hline Preparatory & 2 & 2.5 \\
\hline Secondary & 17 & 21.2 \\
\hline University or more & 5 & 6.2 \\
\hline \multicolumn{3}{|l|}{ Mother's education } \\
\hline Illiterate & 41 & 51.2 \\
\hline Read \& write & 2 & 2.5 \\
\hline Primary & 1 & 1.2 \\
\hline Preparatory & 1 & 1.2 \\
\hline Secondary & 18 & 22.5 \\
\hline University or more & 17 & 21.3 \\
\hline \multicolumn{3}{|l|}{ Father's occupation } \\
\hline Farmer & 39 & 48.8 \\
\hline Governmental employee & 28 & 35.0 \\
\hline Technical worker & 9 & 11.3 \\
\hline Free work & 4 & 5.0 \\
\hline \multicolumn{3}{|l|}{ Mother's occupation: } \\
\hline Working & 5 & 6.2 \\
\hline House wives & 75 & 93.8 \\
\hline \multicolumn{3}{|l|}{ Number of family members } \\
\hline$<5$ & 21 & 26.2 \\
\hline $5-6$ & 37 & 46.2 \\
\hline$>6$ & 22 & 27.5 \\
\hline Mean \pm SD (Range) & \multicolumn{2}{|c|}{$5.69 \pm 1.88(2-10)$} \\
\hline
\end{tabular}




\begin{tabular}{|l|c|c|}
\hline \multicolumn{1}{|c|}{ Characteristics } & \multicolumn{2}{l|}{ No. } \\
\hline Number of rooms & 55 & 68.8 \\
\hline $2-3$ & 14 & 17.5 \\
\hline $4-5$ & 11 & 13.8 \\
\hline$>5$ & $3.56 \pm 1.27(2-8)$ \\
\hline Mean \pm SD (Range) & \\
\hline
\end{tabular}

Table (2): Distribution of disabled adolescent girls according to their changes during puberty and menstrual history at El-Amal and El-Noor Schools, Assiut Governorate, $(n=80)$.

\begin{tabular}{|c|c|c|}
\hline & No. & $\%$ \\
\hline \multicolumn{3}{|l|}{ Changes during adolescence(\#) } \\
\hline Increase weight and height & 61 & 76.2 \\
\hline Hip development & 3 & 3.8 \\
\hline Grow body hair & 59 & 73.8 \\
\hline Breast growth & 67 & 83.8 \\
\hline Sexual dreams & 1 & 1.2 \\
\hline Menstruation & 73 & 91.2 \\
\hline Tenderness and softness in the sound & 7 & 8.8 \\
\hline \multicolumn{3}{|l|}{ Age at menarche } \\
\hline$<12$ years & 20 & 25.0 \\
\hline $12-13$ years & 47 & 58.8 \\
\hline$>13$ years & 13 & 16.2 \\
\hline \multicolumn{3}{|l|}{ Duration of menstrual cycle } \\
\hline$<21$ days & 10 & 12.5 \\
\hline $21-28$ days & 46 & 57.5 \\
\hline$>28$ days & 24 & 30.0 \\
\hline \multicolumn{3}{|l|}{ Presence of the natural discharge: } \\
\hline Yes & 73 & 91.2 \\
\hline No & 7 & 8.8 \\
\hline \multicolumn{3}{|l|}{ Accompanied by itching $($ no. $=73)$} \\
\hline Yes & 31 & 42.5 \\
\hline No & 42 & 57.5 \\
\hline \multicolumn{3}{|c|}{ Consider itching a normal symptoms $($ no. $=31)$} \\
\hline Yes & 18 & 58.1 \\
\hline No & 13 & 41.9 \\
\hline \multicolumn{3}{|l|}{ Towels used per day: } \\
\hline $1-2$ & 38 & 47.5 \\
\hline 3 or more & 42 & 52.5 \\
\hline
\end{tabular}

\# More than one answer was mentioned. 
Table (3): Distribution of disabled adolescent girls according to their pre menstrual syndrome and its management at El-Amal and El-Noor Schools, Assiut Governorate, $(\mathbf{n}=\mathbf{8 0})$.

\begin{tabular}{|l|c|c|}
\hline \multicolumn{1}{|c|}{ Items } & \multicolumn{1}{|c|}{ No. } \\
\hline Menstrual symptoms (\#) & 2 & 2.5 \\
\hline Emotional tension and irritability & 1 & 1.2 \\
\hline Feeling sad and self-contempt & 7 & 8.8 \\
\hline Crying & 7 & 8.8 \\
\hline Fatigue and difficulty concentrating & 1 & 1.2 \\
\hline Sleeping too much & 2 & 2.5 \\
\hline Bloated feeling & 3 & 3.8 \\
\hline Pain in breast & 8 & 10.0 \\
\hline Change in appetite & 80 & 100.0 \\
\hline Abdominal pain & 58 & 72.5 \\
\hline Pain in the back and feet & \multicolumn{2}{|c|}{} \\
\hline Management of symptoms (\#) & 1 & 1.2 \\
\hline Go to doctor & 14 & 17.5 \\
\hline Use of analgesic without prescription & 70 & 87.5 \\
\hline Drink hot fluids & 30 & 37.5 \\
\hline Go to sleeping & \multicolumn{2}{|l|}{} \\
\hline Delayed menstrual period (\#) & 3 & 3.8 \\
\hline Go to physician & 18 & 22.5 \\
\hline Consult my friends & 25 & 31.2 \\
\hline Consult my teacher & 10 & 12.5 \\
\hline Consult a health visitor & 34 & 42.5 \\
\hline Nothing & \multicolumn{2}{|c|}{} \\
\hline
\end{tabular}

\# More than one answer was mentioned.

Table (4): Distribution of disabled adolescent girls' practice about perineal care in pre, post, and follow-up test at El-Amal and El-Noor School, Assiut Governorate, $(n=80)$.

\begin{tabular}{|c|c|c|c|c|c|c|c|c|}
\hline \multirow{2}{*}{ Practice } & \multicolumn{2}{|c|}{ Pre-test } & \multicolumn{2}{|c|}{ Post-test } & \multicolumn{2}{|c|}{ Follow-up test } & \multirow{2}{*}{ P-value1 } & \multirow{2}{*}{ P-value2 } \\
\hline & No. & $\%$ & No. & $\%$ & No. & $\%$ & & \\
\hline Prepare equipment & 80 & 100.0 & 80 & 100.0 & 80 & 100.0 & -- & -- \\
\hline $\begin{array}{l}\text { Wash hands before each perineal } \\
\text { care }\end{array}$ & 12 & 15.0 & 41 & 51.2 & 7 & 8.8 & $0.000 *$ & $0.000^{*}$ \\
\hline $\begin{array}{l}\text { Remove soiled pad from front to } \\
\text { back and discard in waste container }\end{array}$ & 80 & 100.0 & 80 & 100.0 & 80 & 100.0 & -- & -- \\
\hline $\begin{array}{l}\text { Pour warm water or antiseptic } \\
\text { solution over perineum without } \\
\text { opening labia }\end{array}$ & 80 & 100.0 & 80 & 100.0 & 80 & 100.0 & -- & -- \\
\hline \multicolumn{9}{|c|}{ Clean perineum according to the following direction } \\
\hline $\begin{array}{l}\text { a) Clean the mons pubis from the } \\
\text { level of clitoris upward to the } \\
\text { lower abdomen }\end{array}$ & 1 & 1.2 & 78 & 97.5 & 77 & 96.2 & $0.000 *$ & 0.650 \\
\hline $\begin{array}{l}\text { b) Clean two thigh from medial to } \\
\text { lateral }\end{array}$ & 1 & 1.2 & 64 & 80.0 & 36 & 45.0 & $0.000 *$ & $0 \quad .000^{*}$ \\
\hline $\begin{array}{l}\text { c) Clean two labia majora from } \\
\text { upward to downward in a single } \\
\text { motion }\end{array}$ & 1 & 1.2 & 74 & 92.5 & 34 & 42.5 & $0.000 *$ & $0.000^{*}$ \\
\hline $\begin{array}{l}\text { Dry the perineum using the same } \\
\text { technique }\end{array}$ & 16 & 20.0 & 80 & 100.0 & 40 & 50.0 & $0.000 *$ & $0.000^{*}$ \\
\hline Put clean perineal pad & 80 & 100.0 & 80 & 100.0 & 80 & 100.0 & -- & -- \\
\hline Wash hands after each perineal care & 77 & 96.2 & 80 & 100.0 & 52 & 65.0 & 0.080 & $0.000^{*}$ \\
\hline
\end{tabular}

P-value1: Comparison between pre-test and post-test

P-value2: Comparison between post-test and follow-up.

Chi square test 
Figure (1): Distribution of disabled adolescent girls according to their sources of information about reproductive health at El-Amal and El-Noor School, Assiut Governorate, $(n=80)$.

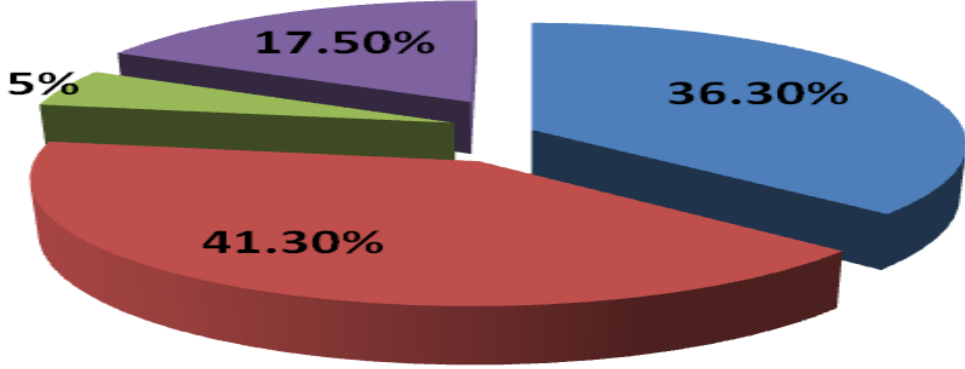

Mothers

Friends

Mass media

Seminars

Figure (2): The total score of disabled girls' knowledge about reproductive health in pre, post and follow-up test at El Amal and El Noor School, Assiut Governorate, $(n=80)$.

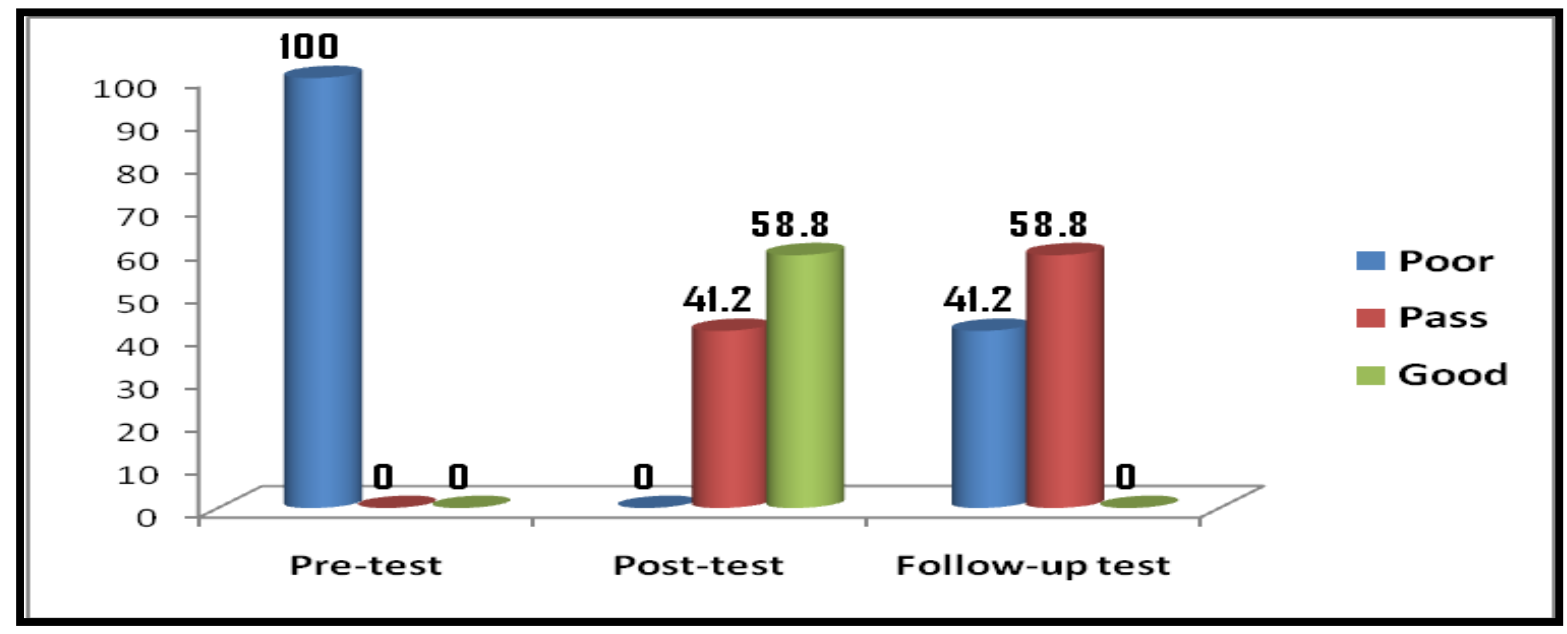

Figure (3): The total score of disabled girls' attitude toward reproductive health in pre, post and follow-up test at El Amal and El Noor School, Assiut Governorate, $(\mathrm{n}=\mathbf{8 0})$.

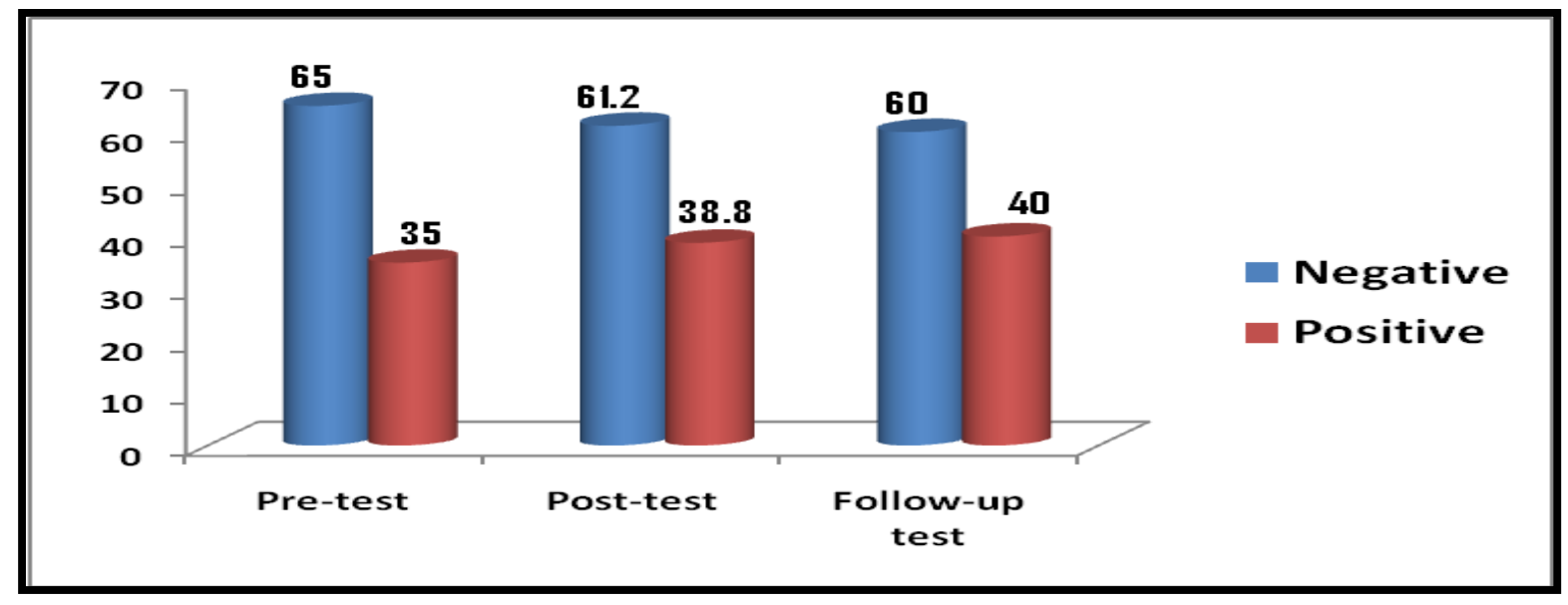


Figure (4): The relation between total score of disabled girls' attitude towards reproductive health and type of disabilities in follow-up test at El-Amal and El-Noor School, Assiut Governorate, $(n=80)$.

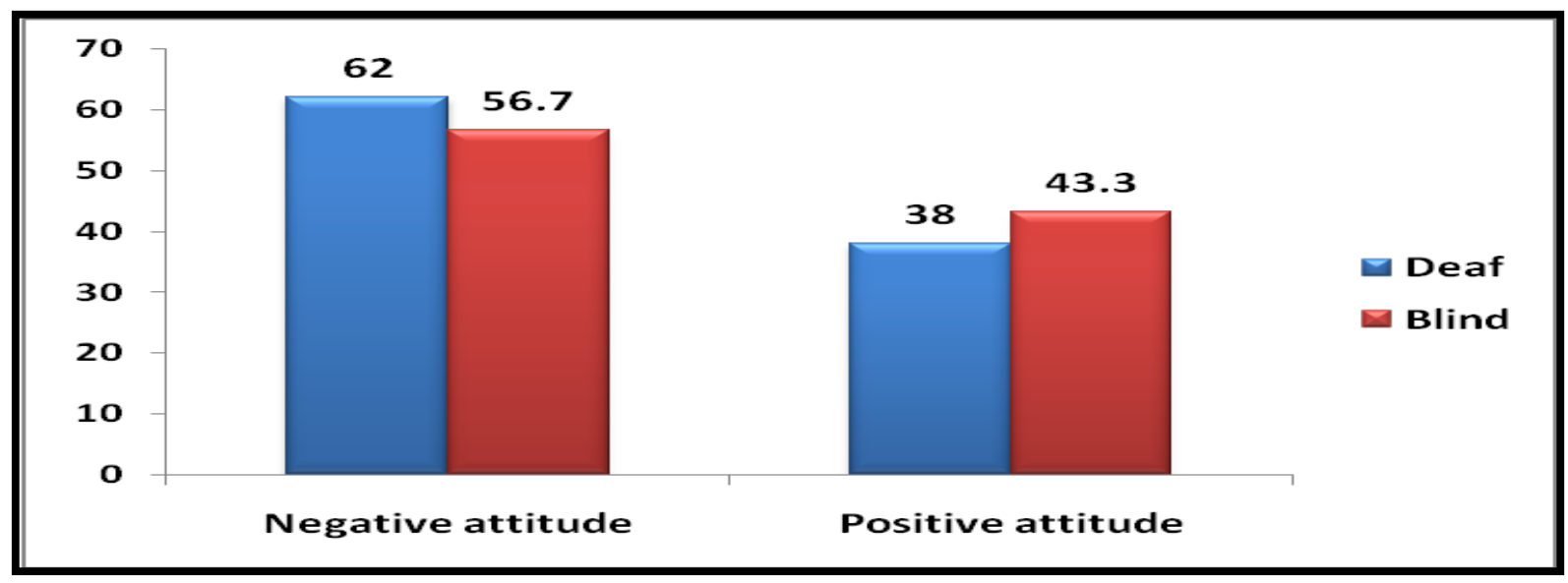

Figure (5): The relation between total score of disabled girls' knowledge and type of disabilities in follow-up test at El-Amal and El-Noor School, Assiut Governorate, $(\mathbf{n}=\mathbf{8 0})$

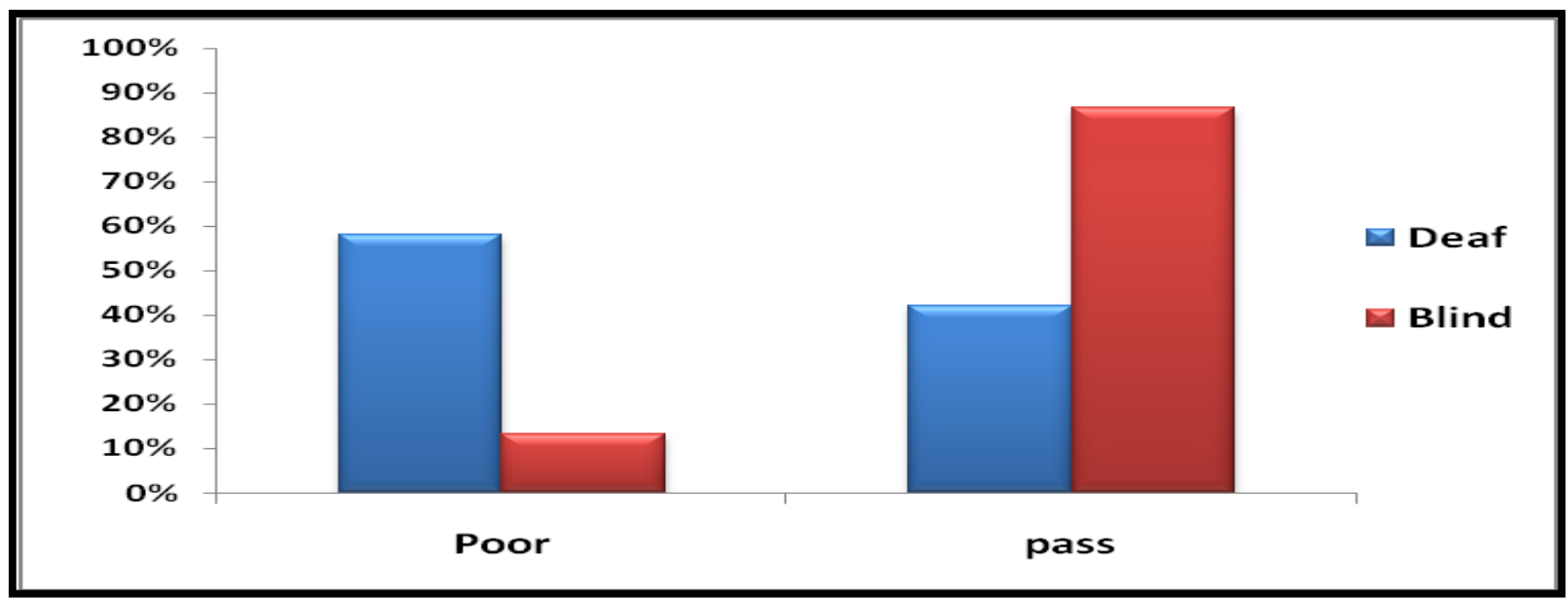

Table (1) showed that $36.2 \%$ of the studied girls their ages ranged from $16-<18$ years and more than two fifths $(42.5 \%)$ of them were in secondary school. Regarding to residence, it was found that the vast majority of them $(92.5 \%)$ were from rural areas and $97.5 \%$ of them residing in the school. According to parents' education; the table cleared that $53 \%$ of fathers and $41 \%$ of mothers were illiterate. Also, nearly half $(48.8 \%)$ of fathers were farmers and the vast majority $(93.8 \%)$ of mothers were house wives.

Table (2) revealed that the vast majority of them $(91.2 \%)$ mentioned menstruation as one of their changes during adolescence also, $83.8 \%$ of them mentioned breast growth. According to age at menarche and duration of menstrual cycle, more than half of them $(58.8 \%)$ their menstruation started in age 12 - 13 years, all of them $(100 \%)$ their normal menstrual period ranged from 3-7 days and 57.5\% their menstrual cycle ranged from $21-28$ days.
Table (3) showed that all of the studied girls (100\%) illustrated abdominal pain, $72.5 \%$ of them mentioned pain in the back and feet as pre menstrual syndrome. It was found that $87.5 \%$ of the studied girls drink hot fluids to manage their menstrual symptoms, while $17.5 \%$ of them use analgesic without prescription. Also table (3) showed that only $3.8 \%$ of them go to physician when their menstrual period were delayed.

Table (4) showed the distribution of the studied girls according to practice of disabled adolescent girl's about perineal care in pre, post, and follow-up test. It was cleared that all of the studied girls(100\%) do these steps in pre, post, and follow-up test which included (Prepare equipment, remove soiled pad from front to back and discard in waste container, pour warm water or cleansing solution over perineum, and put clean perineal pad). While $(15.0 \%)$ of them wash her hands before each perineal care in pre test and their practice improved in post test $(51.2 \%)$ and after 
three months follow up their practice declined to $(8.8 \%)$.

According to their source of information about reproductive health figure (1) showed that $(41.3 \%)$ of the studied girls heard about reproductive health from their friends, $(36.3 \%)$ from their mothers, while only $(5.0 \%)$ of them heard from mass media.

Figure (2) revealed that all the studied girls(100\%) have poor knowledge in pre test while their knowledge improved in post test to (pass $=41.2 \%$ ) and (good $=58.8 \%)$. After three months for follow up test their knowledge slightly declined to (pass = $58.8 \%$ ). Finally the figure indicated that highly statistically significant difference between disabled girls' knowledge in pre, immediate post test and follow-up $(\mathrm{P}=\leq 0.001)$.

Figure (3) cleared that there was no statistically significant difference between total score of disabled girls' attitude toward reproductive health in pre, post and follow-up test $(\mathrm{p}=0.794)$.

Figure (4) revealed that there was no statistically significant difference between total score of disabled girls' attitude with types of disability $(\mathrm{P}=0.637 \#)$.

Figure (5) cleared the relation between total score of disabled girls' knowledge and type of disabilities in follow-up test. The figure indicated that there was highly statistically significant difference between disabled girls' knowledge and type of disabilities in follow-up test $(\mathrm{P}=0.000)$

\section{Discussion}

Access to reproductive health information is often not available to youth with disabilities, or disseminated through such inappropriate means as inaccessible disabilities, clinics, inaccessible print or electronic media, or by providers who cannot communicate with youth with disabilities. Few education programmes cater to the reproductive needs of youth with disabilities. For example, in several countries youth with disabilities often do not receive advice on HIV/AIDS, as the clinics are physically inaccessible, material is not available for those with visual impairments, and providers are unable to communicate in sign language. Moreover, most health care professionals have no disability awareness and consequently feel unwilling or unable to address their issues (Yousafzai et al., 2004).

As to the knowledge of the researcher, few studies have been carried out among disabled young people concerning to sexual reproductive health especially in middle east. Also, all researches which carried out in the developed countries had different topics in reproductive health which include if the studied sample had sexual intercourse, types of contraceptive used during their first sexual encounter, unintended pregnancy, history of abortion, history of ever having STI, and use of condom. All of these topics didn't fit with our communities. So, the present study aimed to assess knowledge, attitude, and practice of disabled adolescent girls and evaluate the impact of educational program regarding to reproductive health for disabled adolescent girls.

With regard to socio demographic characteristics of the studied sample, the present study showed that all the studied sample were female, less than two third of them were deaf and 37.5 of the participant were blind. According to their ages, it ranged between < $16: \geq 18$ years old, and more than two quarter of them were secondary school. Regarding the residence, it was found that the vast majority of them were from rural areas and residence in school. Most of the studied samples were residing in the schools, because schools were far from their living places also, there were many difficult in transporting from their homes to schools every day, especially among the blind girls.

This result disagreed with Mulindwa (2003) who conducted study on reproductive health and HIV/AIDs among persons with disabilities in Kampala, Katakwi and Rakia districts. The participant were men and women with disabilities which include $(12.3 \%$ with deafness, $33.3 \%$ were blind, and other disability (Handicap-upper limb, Handicaplower limb, Handicap-both limbs, Mental disorder). According to their ages thirty seven percent of the female respondents were youth (15-24), for the men, thirty one were youth. Also, according to their educational level, the majority of female respondents had attained only primary school education and all of them were from urban areas. Education affects many aspects of one's life including individual demographic and health behaviour. Educational level is strongly associated with one's knowledge and perceptions about reproductive health aspects.

On other hand, according to age at menarche more than half of the sample; their menstruation started in age $12-13$ years while, and menstrual cycle ranged from 21 - 28 days. Regarding to their menstrual symptoms' history all of the studied sample illustrated abdominal pain, and around three quarters of them mentioned pain in the back and feet during menstruation. Previous studies have shown that up to eighteen percent of adult women with disabilities have premenstrual syndrome, compared with only five percent of the general female population. Adolescents with disabilities are more likely to have menstrual problems than the general female population (Jeffery et al., 2013).

This result revealed that all the studied girls have poor knowledge in pre test while their knowledge improved in post test to (pass equal slightly more 
than two fifth) and (good equal more than half of them). After three months for follow up test their knowledge slightly declined to (pass equal slightly more than two fifth). It agreed with survey conducted in Ghana by Mprah, 2013 (Sexual and reproductive health needs assessment with deaf people: Methodological challenges and ethical concerns) findings from the survey indicated that the level of knowledge on SRH issues amongst deaf people ، particularly amongst adolescents, was low, possibly due to limited access to professional sources of information. Also, these results agreed with The National Family Planning Board, 2011 which showed that adolescents with disabilities, whether blind, deaf or suffering from intellectual or physical disability have important gaps in their SRH knowledge.

A review of literature showed that there is a positive correlation between the knowledge and behavior. Although behavioral changes are usually the ultimate goal for health education programs, an increase in knowledge does not always cause behavior to change. It is, however, a prominent element in health education and is a necessary factor in changing some health behaviors (World Youth Alliance, 2012; Wahba \& Fahimi, 2012).

For the perineal care, the present study showed that all of the studied girls do these steps in pre, post, and follow-up test which included (Prepare equipment, remove soiled pad from front to back and discard in waste container, pour warm water or cleansing solution over perineum, and put clean perineal pad). Also, the present study revealed that only one from disabled girl did these steps (clean the mons pubis from the level of clitoris upward to the lower abdomen, clean two thigh from medial to lateral, and clean two labia majora from upward to downward in a single motion) in pre test while their practice improved in post test.

The present study indicated that there was highly statistically significant difference between disabled girls' knowledge and type of disabilities in follow-up test $(\mathrm{P}=0.000)$. In my opinion blind girls can gain information faster than deaf girls because blind girls can communicate with others by listening and talking while deaf girls need experts in sign language to communicate with them.

According to their sources of information about reproductive health the present study showed that less than half of the studied girls heard about reproductive health from their friends, more than one third from their mothers while only $5.0 \%$ of them heard from mass media. This could be due to lack of proper communication between mother and their daughters owing to traditional taboos, they feel awkward and embarrassed to discuss on this subject and TV programmes didn't accompany by sign language for deaf girls or any media for blind girls.

The results showed that the studied girls' knowledge improved in post test to (pass equal slightly more than two fifth) and (good equal more than half of them). After three months for follow up test their knowledge slightly declined to (pass = good equal more than half of them). It could be interpreted that the students in the period of follow up test they were preparing for the final exam at the school, which negatively affected their concentration with the researcher. Also, the duration of the program was short so, it was necessary to prolong the duration of the program. Toward Al Amal students, the researcher has difficult to communicate with them because they need sign language. Also, lack experts with sign language in the school especially in discussed the anatomy of reproductive system which will affect in understanding of the program.

\section{Conclusion and recomendation}

Based on the results of the present study; it could be concluded that; All the studied girls have poor knowledge in pre test while after implementation the education programe their knowledge were improved. Regarding to perineal care, all of the studied girls carried out all steps of perineal care except three steps which include the correct direction for cleaning the perineum while their practice improved in post and follow up test. There was no statistically significant difference between total score of disabled girls' attitude toward reproductive health in pre, post and follow-up test .

Based on the results of the present study, it was recommended that

1. Continues health education programs should be implemented for increasing awareness of adolescents with disabilities about reproductive health

2. Training of RH service provider in Sign and Braille language in order to guarantee confidentiality among young people with hearing and vision impairment, which is the cornerstone of RH service utilization when this segment of populations are considered.

3. The nursing curriculum should include reproductive health for adolescents with disabilities.

4. Further studies should be conducted in reproductive health care needs of adolescents with disabilities. 


\section{References}

1. Allender J., Rector C., \& Warner K., (2005): Community \& Public Health Nursing: Promoting the Public's Health printed by Wolters Kluwer health, LippinCott Williams \& Wilkins.

2. Ibrahim H., Ahmed A., Gadallah M., and Hussien A., (2009): Nutritional and exercise habits for prevention of osteoporosis among female adolescents in Assiut City secondary school, the new Egyptian journal of medicine vol:41;No:4 ,P.P 346-356.

3. International Labour organization (ILO), (2009): Facts On Disability and Decent Work available http://www.ilo.org/disability Issued July 2012.

4. Jeffery E., Kayani S., Garden A., (2013): Management of menstrual problems in adolescents with learning and physical disabilities. Journal of The Obstetrician \& Gynaecologist.volume 15, issue 2, P.P 106-112.

5. Mohamed H., \& El-Nagger N., (2012): Effect of Self Perineal Care Instructions on Episiotomy Pain and Wound Healing of Postpartum Women Journal of American Science, 2012; volume 8, issue 6.

6. Mprah W., (2013): Sexual and reproductive health needs assessment with deaf people in Ghana: Methodological challenges and ethical concerns. African Journal of Disability; Vol 2, No 1.

7. Mulindwa I., (2003): Study On Reproductive Health And HIV/Aids Among Persons With Disabilities In Kampala, Katakwi And Rakai Districts (Knowledge, Attitudes and Practices). Commissioned by Disabled Women's Network and Resource Organization (DWNRO) with Support from Action Aid Uganda.

8. Smeltzer, S., (2013): Improving Health and Wellness of People with Disabilities. International Encyclopedia of Rehabilitation. Available online: http://cirrie.buffalo.edu/encyclopedia/en/article/3 $00 /$

9. TARSHI, 2010: sexuality And disability in the Indian context. Available at http://www.tarshi.net.

10. The National Family Planning Board, (2011): Realising The Sexual And Reproductive Health Rights Of Adolescents Vol 1, Issue 6 (August, 2011).

11. UNFPA, 2009: Sexual and reproductive health of persons with disabilities http://www.un.org/disabilities/convention/pdfs/fa ctsheet.pdf.
12. UNICEF, (2012): Fast facts on Adolescents and Youth in Latin America and the Caribbean. Consulted on March 18, 2012. Available at www.unicef.org/media/files/Fast_facts.

13. USAID (2001): Population report 29 (3):2-33. Available at http://www.usaid.gov.

14. Wahba M., \& Fahimi F., (2012): The Need For Reproductive Health Education In Schools In Egypt, Population Reference Bureau.

15. WHO, (2008): reproductive health Available at: http://www.who.int/nmh/.

16. WHO, (2009): Promoting sexual and reproductive health for persons with disabilities: WHO/UNFPA guidance note. Geneva: available at http://whqlibdoc.who.int/publications/2009/9789 241598682_eng.pdf. Accessed June 30, 2010.

17. WHO, (2011): World report on disability. Available at: http://www.who.int/nmh.

18. WHO, (2013): Adolescent health. available at http://www.who.int/topics/adolescent_health/en.

19. World Youth Alliance, (2012): Reproductive Health | White Paper February 2012. Available at http://www.wya.net/

20. Yousafzai A., Phindile J., Groce N., Wirz S., (2004): Knowledge, personal risk and experiences of HIV/AIDS among people with disabilities in Swaziland, International Journal of Rehabilitation Research 2004;27(3):247-51. 